\title{
Gold and the Atomic Theories of the Seventeenth Century
}

\author{
M. P. Crosland \\ Department of Philosophy, University of Leeds
}

In the late sixteenth and early seventeenth century there was a growing feeling that the way to gain an understanding of nature was not to consult the ancient authorities but to turn to the world of experience. An increasing concern with observational evidence led to attempts to modify experience in some way to gain greater knowledge. This modification of experience led to the development of the experimental method.

Aristotle's considerable influence in western civilisation opposed the idea of matter consisting of atoms but in the early seventeenth century his influence was declining. In this Galileo played no small part. Yet even before Galileo, scholars were looking again at the old texts and rediscovering the ancient atomists. The idea of matter consisting of corpuscles was to be an immensely fruitful concept in seventeenth century natural philosophy but before the idea could be taken seriously it had to overcome various objections. Two quite different barriers to acceptance were religious and experimental. The French priest Pierre Gassendi had to show his contemporaries that, although atomism had been part of the doctrine of the atheist Lucretius, a belief in atoms in no way implied the undermining of Christianity. The second obstacle was more per-

\section{Galileo Galilei \\ 1564-1642}

A Native of Pisa, Galileo studied and then taught in the university there, becoming Professor of Mathematics at Padua in 1592. After his work on falling bodies, the construction of the first useful telescope and the publication of his views on planetary motion he resigned his chair in 1610 to return to Florence as Court Mathematician and Philosopher to the Grand Duke Cosimo de Medici of Tuscany. Publication of his dialogue concerning the two chief world systems led to his trial and sentence of house arrest by the Inquisition in 1633. His great scientific achievements were matched by his polemical gifts and his sarcastic demolition of arguments advanced by his enemies From the portrait painted in 1635 by Justus Sustermans, now in the Uffizi Gallery in Florence manent. How could the new natural philosophy provide evidence of the existence and properties of tiny corpuscles inaccessible to observation? Although direct evidence was difficult to obtain there was plenty of indirect evidence, beginning with phenomena observed in everyday life. Galileo remarked that one may carry a ball of musk which will fill a thousand rooms with odour and yet if it is weighed at the end there will be no diminution found. Thus it is possible to have a diminution of matter which is so slight as to be imperceptible to even the most sensitive balance.

In his book Il Saggiatore (The Assayer) published in Rome in 1623, Galileo addressed his opponent Horatio Grassi who had written under the pen name of "Lothario Sarsi". Grassi had attacked Galileo in a book entitled The Astronomical and Philosophical Balance, in which "balance" he pretended to weigh some of his opponent's arguments. Galileo kept up this metaphor in his reply, calling his book The Assayer. Although the title is purely metaphorical, Galileo does use gold in an example:

"Let me ask Sarsi whether he thinks any difference of weight could be detected in a silver button before and after it is gilded. He must say no, as we see gold reduced to such thin leaf that it will sustain itself upon the quiet

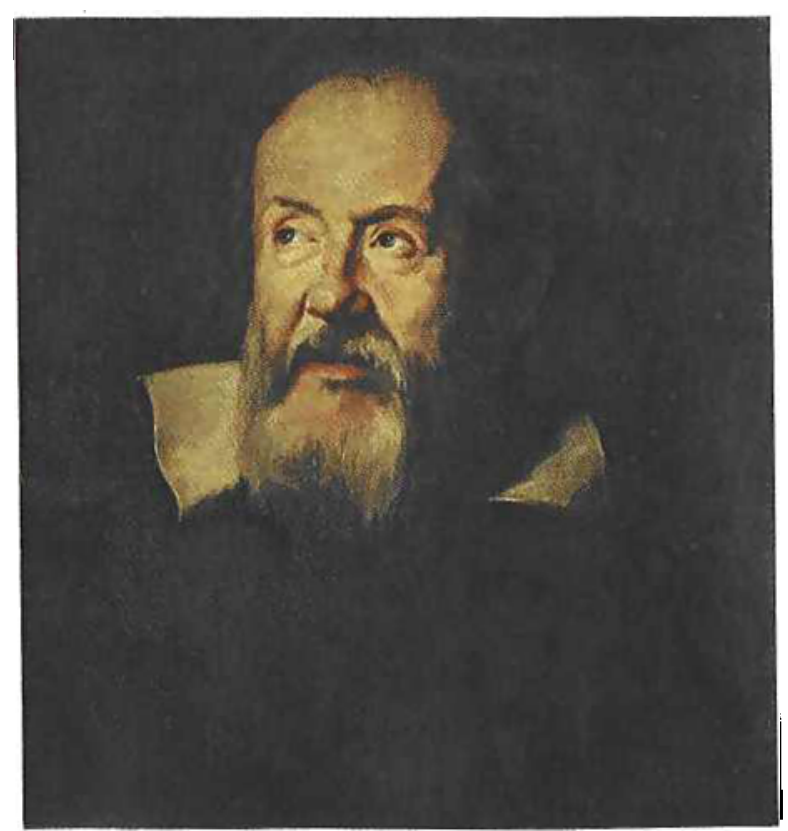


The drawing of gold-clad silver wire as depicted by Vannoccio Biringuecio in his "Pirotechnia", published in Venice in 1540. "The wire may be drawn out so fine" he wrote "that the eye can scarcely perceive it, yet it is always well gilded all over'. First Galileo and then Halley based arguments on this technique to make valuable contributions to the under. standing of matter and to the atomic theories of their period

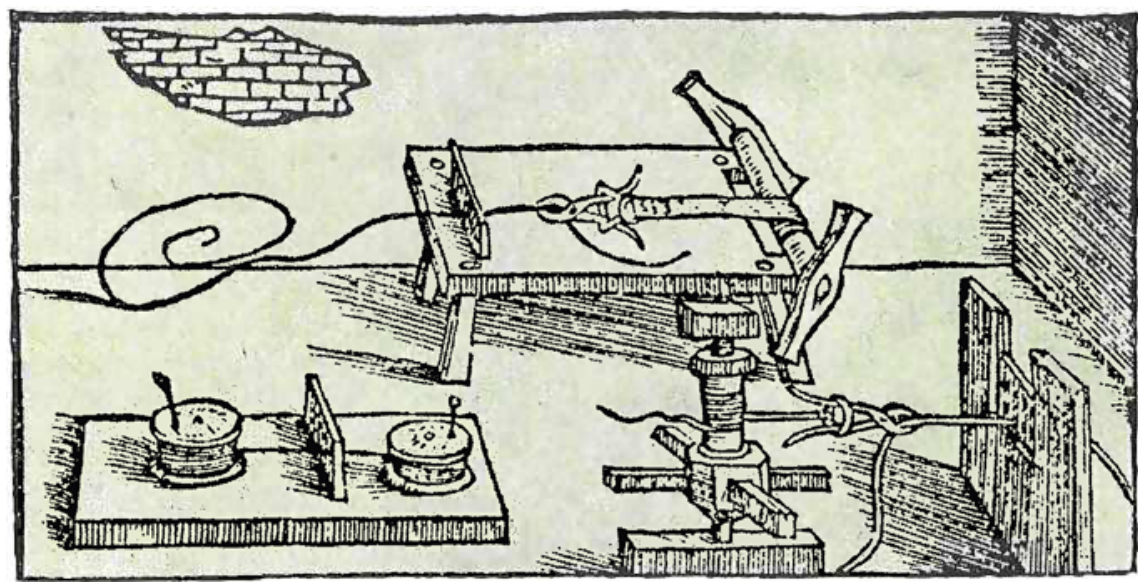

air and drop with extreme slowness; and with such gold any metal may be gilded. Now this button may be used two or three months before the gilding will wear off, and yet since the gilt is ultimately consumed it must be diminished every day and even every hour." (1)

Galileo's later Dialogue Concerning Two New Sciences, published in 1638 , is remembered primarily because it laid the foundations of modern statics and dynamics. However, the book also raised other problems such as that of indivisibles, both in a mathematical and a physical sense. One of the characters in the dialogue, Salviati (representing Galileo) argued that "a continuous quantity is built up of absolutely indivisible atoms."(2) The Aristotelian Simplicio replied that on such a hypothesis

"an ounce of gold might be rarefied and expanded until its size would exceed that of the earth",

which seemed ridiculous. But Salviati was ready with an answer:

"I am not able to render the invisible visible, nor do I think you will ask this. But now that you mention gold, do not our senses tell us that that metal can be immensely expanded? I do not know whether you have observed the method employed by those who are skilled in drawing gold wire, of which really only the surface is gold, the inside material being silver. The way they draw it is as follows: they take a cylinder or, if you please, a rod of silver, about half a cubit long and three or four times as wide as one's thumb; this rod they cover with gold leaf, which is so thin that it almost floats in air, putting on not more than eight or ten thicknesses. Once gilded they begin to pull it, with great force through the holes of a draw plate; again and again it is made to pass through smaller and smaller holes until, after many passages, it is reduced to the fineness of a lady's hair, or perhaps even finer; yet the surface remains gilded. Imagine now how the substance of this gold has been expanded and to what fineness it has been reduced."(3)

Simplicio thought that in drawing out the wire the area would not be increased as "one dimension compensates for another". Salviati, however, asserted that the surface would increase directly as the square root of the length and he demonstrated this geometrically. Thus if a silver rod of half a cubit is drawn out into a length of 20,000 cubits, the surface area would have increased 200 times:

"Consequently the ten leaves of gold which were laid on have been extended over a surface two hundred times greater, assuring us that the thickness of gold which now covers the surface of so many cubits of wire cannot be greater than one-twentieth that of an ordinary leaf of beaten gold. Consider now what degree of fineness it must have and whether one would conceive it to happen in any other way than by enormous expansion of parts; consider also whether this experiment does not suggest that physical bodies are composed of infinitely indivisible particles a ...".(4)

Galileo scholars are divided between two extreme positions, one regarding him as a Neoplatonist mathematician and the other stressing the technological background of his work. Thus the Two New Sciences opens with a comment by Salviati:

"The constant activity which you Venetians display in your famous arsenal suggests to the studious mind a large field for investigation, especially that part of the work which involves mechanics."

This "externalist" interpretation of Galileo finds further support in the example we have quoted about wire drawing. The "corpuscular philosophy" which was to become so fashionable in the seventeenth century may not have had its origins in the technology of the time but it certainly found support there. It is significant that Galileo, no ivory-tower scholar, should have been familiar with the work of tradesmen and artisans. The old techniques of gilding were used by him as further evidence for the existence of tiny corpuscles. The great ductility and malleability of gold enabled Galileo and others to use this metal to make a valuable contribution to the understanding of matter.

In Galileo's time a case had to be made out for the existence of tiny particles. By the second half of the seventeenth century corpuscular theories of matter were widespread and attention turned to the determination of the size of the ultimate particles. There were many different approaches to this problem. To illustrate how wide were the possibilities we may 


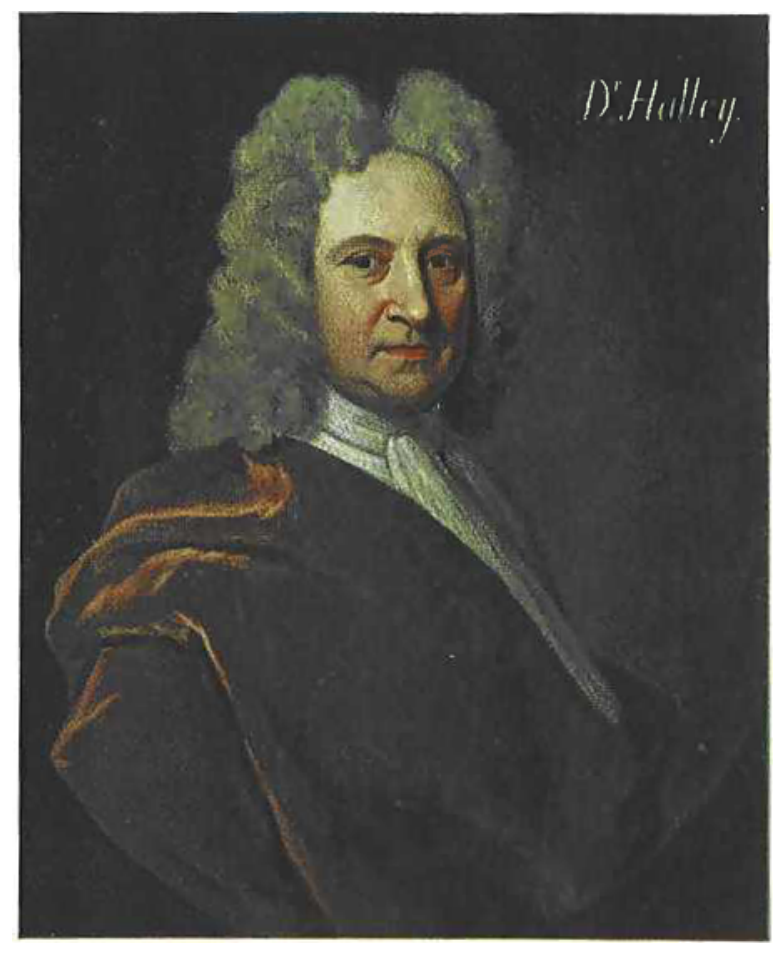

Edmund Halley

1656-1742

Born in London and educated at St Paul's School and at Queen's College, Oxford, Halley was elected a Fellow of the Royal Society at the age of only 22 . He is, of course, best known for the great part he played, when Secretary of the Royal Society, in securing at his own expense the publication of Newton's Principia and for his accurate predictions of the return of the comet named after him, but his scientific interests and published papers covered a much wider field From the portrait by Richard Phillips in the National Portrait Gallery

mention Walter Charleton's attempt in 1654 to estimate their size by calculating the dispersion of one grain of frankincense in a large room. (5) Gold, however, provided a more precise method of approach, and it was a method reminiscent of Galileo that was advocated by Halley in a paper read to the Royal Society in 1689. (6)

Edmund Halley is known principally as an astronomer and the man who, in 1687, persuaded Isaac Newton to bring his Principia Mathematica to the stage of publication. Halley's fame was doubly assured when the comet of 1682, which he had predicted would come near the earth in 1758 , duly reappeared in the night sky. Halley's other scientific

The first page of Halley's paper, read to the Royal Society on October 16th, 1689, in which he attempted to establish the size of the atoms of gold work and his speculations outside astronomy are generally overlooked, yet they include a theory of matter which was to be taken over and developed by Newton. The theory is highly speculative but Halley was able to provide it with some experimental basis. He chose gold to calculate the order of magnitude of atoms, but whereas Galileo had based his arguments largely on proportion and had recourse to geometry to demonstrate the effect, Halley's approach was more physical. His argument was based on the weight of gilded wire as a fraction of the weight of gold used by the wire drawers. After the introductory paragraphs reproduced below, he writes:

"Being desirous to examine this notion of the magnitude of atoms of gold, I bethought myself of the extreme ductility of that metal, which is seen in the beating of it into leaf, and above all in the drawing fine gilt wire; by means whereof, I believed I might most exactly obtain the true thickness of the coat of gold that appears even with the microscope, so well to represent gold itself, that not the least point of silver appears through it. In order to this, I informed myself among the wire drawers, what gold they used to their silver, and they told me, that the very best double gilt wire, was made out of cylindric ingots 4 inches in circumference, and 28 inches long, which weigh 16 pounds troy; on these they bestow 4 ounces of gold, that is, to every 48 ounces of silver one of gold: and that two yards of the superfine wire weighs one grain. Hence at first sight it appeared, that the length of 98 yards is in weight 49 grains, and that a single grain of goid covers the said 98 yards, and that the tenthousandth part of a grain is above one-third of an inch long; which yet may be actually divided into ten, and so the hundred-thousandth part of a grain of gold be visible without a microscope. But being desirous to compute

An account of the Mea/ure of the thicknefs of Gold upon Gilt-Wire, toget ber with a demonftration of the exceeding minutene/s of the Atoms or conftituent Particles of Gold; as it was read before the R. Society, by E. H $\mathbf{L} \mathbf{1} \mathrm{x}$.

W THat are the Conftituent parts of Matter, and Vy how there comes to befo great a diverfity in the weight of Bodies to all appearance equally folid and denfe, fuch as are Gold and Glafs, (whofe fpecifick Gravi. ties are nearly as 7 to 1) feems a very hard queftion to thofe that Phall rightly confider it:. For from undoubted experiment, Gravity is in all Bodies proportionable to the quantity of Matter in each, and there is no fuch thing as a propenfion of fome mone, others lefs, towards the Earnhisenters fince the Impediment of of the Air being rewored, all Bodies defcend, be they never fo loofe or compact in texture, with equal velocity. It follows therefore, That there is 7 times as much matter in Gold as in a peice of Glafs of the fame Magnitude, and confequently, that ae leaft fix parts of feven in the bulk of Glafo, mufs be Pore or Vacuity: This fowse favourets of the Atomical-Philofophy have endeavoured to Solve, by fuppofing the primary or conflituent Atoms of Gold to be much larger than thofe of other. Bodies, and confequently the Pores fewer; whereas in other Bodies, the great antritude of the interfperoed Vacustics does diminifh their Weights. 
the thickness of the skin of gold: by means of the specific gravities of the metals, viz. silver $10 \frac{1}{3}$, and gold $18 \frac{2}{3}$, I found the diameter of such wire the 1/386 part of an inch, and its circumference the $1 / 123$ part; but the gold in thickness not to exceed the $1 / 134,500$ part of an inch; whence it may be concluded, that the cube of the hundredth part of an inch would contain above $2,433,000,000$ (or the cube of 1,345 ) of such atoms. And it may likewise be marvelled at, that gold being stretched to so great a degree as is here demonstrated, should yet show itself of so even and united a texture, as not to let the white colour of the silver under it appear through any the least pores; which argues that even in this exceeding thinness, very many of those atoms may still lie one over the other: which is a consideration may merit the thoughts of this honourable society, as tending to examine that renowned atomical doctrine, which has of late of much obtained among the learned."

One might well ask why an astronomer should be concerned with a theory of matter. Two kinds of answers may be given. First, modern specialisation was quite foreign to the seventeenth century and if one was interested in natural philosophy (that is, in science) this could include chemistry and astronomy. Indeed, in the same year in which Halley read his paper on atoms he had been examining the solution and crystallisation of salt from the point of view of density and atomism. However, the problem of the constitution of matter arose also in a purely astronomical context. The same issue of the Philosophical Transactions of the Royal Society that contains his paper on atomism also contains his "Hypothesis of the Structure of the Internal Parts of the Earth". If the density of the moon is greater than the density of the earth in the ratio 9:5 as Newton had said in the Principia,

\footnotetext{
"Why may we not reasonably suppose the Moon, being a small Planet, to be solid Earth, Water and Stone and this Globe to consist of the same materials, only four-ninths thereof to be cavity, within and between the internal Spheres."(7)
}

It was precisely in the context of explaining why the density of gold should be nearly seven times greater than that of glass that Halley had considered the size of gold atoms. He said that the essential physical difference between glass and gold was that there were more empty spaces or pores in glass. A possible explanation was that the atoms of gold were larger.

It was through Newton that Halley's work had its greatest influence. Halley's explanation of the difference between glass and gold in terms of the greater number of pores in glass could be applied as a simple model in optics to explain why glass is transparent and gold opaque. Newton argued that "Bodies are much more rare and porous than is commonly believed" and was concerned to show that even gold, that standard example of a massy, opaque substance "has more Pores than solid parts". (8) Thus matter only filled a small part of space.
Joseph Priestley expressed this dramatically when he said that "all the solid matter in the solar system might be contained within a nut-shell". (9) This attitude downgraded the role of matter in nature and had important implications for philosophy, theology and science.

Most of this paper has been concerned with the physical properties of gold, and particularly its ductility, as useful evidence for a corpuscular theory of matter. However, despite the comparative lack of chemical activity of gold, certain of its chemical reactions were known in the seventeenth century, notably its reaction with "aqua regia". At a time when all chemical reactions were viewed as mysterious transmutations, Robert Boyle (1627-91) used gold to provide clear evidence of the persistence of identity through change. A theory was not very helpful to chemistry which allowed some things to disappear and other quite different substances to take their place. It was the contribution of the atomic theory of the seventeenth century to state that a chemical reaction consisted not of a transmutation but rather of a rearrangement of atoms. In his Sceptical Chymist Boyle wrote:

"I consider then that gold will mix and be colliquated not only with silver, copper, tin and lead, but with antimony, regulus martis and many other minerals, with which it will compose bodies very differing both from gold, and the other ingredients of the resulting concretes. And the same gold will also by common aqua regis, and (I speak knowingly) by divers other menstruums, be reduced into a seeming liquor, insomuch that the corpuscles of gold will, with those of the menstruum, pass through cap-paper, and with them also coagulate into a crystalline salt. And I have further tried, that with a small quantity of a certain saline substance I prepared, I can easily enough sublime gold into the form of red crystals of a considerable length; and many other ways may gold be disguised, and help to constitute bodies of very differing natures both from it and from one another, and nevertheless be afterward reduced to the self-same numerical, yellow, fixed, ponderous, and malleable gold it was before its commixture."'(10)

Gold, therefore, provided clear evidence that chemical reactions involve the rearrangement of the particles of bodies rather than their destruction. Boyle made it his business to provide all the evidence that chemistry would supply to support a corpuscular view of matter. If Boyle had believed in elements, as did Lavoisier, then he would have listed gold and silver among the elements. However, we must not make a mistake of attributing ideas which came a hundred years later to the pioneers of the seventeenth century.

Halley's calculations had shown that even the "large" atoms of gold were of a size well below the observational level. In fact atoms could not play any significant part in chemistry until they could be associated with the elements of Lavoisier in 1789. 
This was the achievement of John Daiton who worked out his atomic theory during the years 1803 to 1808 . By assigning relative weights to the atoms Dalton was to give them a positive meaning which could be related to chemical practice. The exercises of Halley and others in the seventeenth century could only lead to despair or wonder. As man was beginning to learn of the immensity of space he was also learning of the existence of a micro-world equally inaccessible to his direct experience. Man was becoming the measurer rather than the measure of all things.

\section{References}

1 Discourse and Opinions of Galileo, translated by Stillman Drake, New York, Doubleday, 1957, p. 267
2 Dialogue Concerning Two New Sciences, translated by Henry Crew and Alfonso de Salvio, New York, Macmillan, 1914, p. 48

3 Ibid., pp. 52-53

4 Ibid., pp. 54-55

5 More details of this and other contributions to matter theory are discussed in M. P. Crosland, The Science of Matter. A Historical Survey, London, Penguin paperback, 1971

6 Phil. Trans. Roy. Soc., 1691, 16, (194), pp. 541-2

7 Ibid., (194), p. 575

8 Opticks, Book Two, Part III, 4th edition, London 1730 , Dover reprint, New York, 1952, p. 267

9 Priestley, Disquisitions Relating to Matter and Spirit, London, 1777, p. 17. Annold Thackray, Atoms and Powers. An Essay on Newtonian Matter Theory and the Development of Chemistry, Cambridge, Mass., 1970

10 Robert Boyle, Sceptical Chymist, 1661, modern edition, Dent, 1911 , p. 31

\section{Advances in Gold Extraction and Refining}

Gold Metallurgy in South Africa EDITED BY R. J. ADAMSON

Pp. XI and 452. Chamber of Mines of South Africa, Johannesburg, R14.00

Since the beginning of gold mining on the Witwatersrand in 1886 the total amount of gold extracted in South Africa has reached one thousand million ounces, or more than thirty thousand tons. This immense output-obtained from over 3,000 million tons of ore-has been achieved by a combination of technical expertise and co-operative effort in the development of improved methods of ore treatment, smeiting and refining.

When the Witwatersrand reef was first exploited, established methods of extraction then in use elsewhere in the world were naturally adopted or adapted, but these were quickly followed by more advanced and specialised processes designed to ensure the maximum recovery of gold from the relatively low grade of ore. It is now well over twenty years since a text book covering these techniques was made available-King's "Gold Metallurgy on the Witwatersrand" was published in 1949-and developments in the meantime, particularly those stimulated by the opening of the newer mines in the Orange Free State, have made the methods then described no longer representative of current practice.

While the basic methods of concentration and cyanidation introduced many years ago still form the most satisfactory and economical means of extraction, many improvements have been made in their application and in the necessary equipment, and it is mainly in order to describe these more recent developments that the preparation of this book has been undertaken by a team of metallurgists, drawn from the major mining groups and from the National Institute for Metallurgy, under the chairmanship of Mr Adamson, Metallurgical Consultant to the Chamber of Mines.

Because gold in South African ores is intimately associated with a matrix of quartz and other minerals the first step towards its recovery involve comminution to fine particle sizes in order to release the gold for further treatment. The successive stages of crushing and grinding, milling and classification are described at length, with full details of developments in the mechanical equipment. Gravity concentration pro- cedures are similarly discussed, followed by a full account of the cyanidation process first introduced by MacArthur and the Forrest brothers in 1890 but nowadays characterised by much more sophisticated filtration practice and operated as a continuous instead of a batch process.

Precipitation of the gold from the cyanide solution is effected by means of metallic zinc, the gold slimes being separated in pressure filters. These are acid-treated to remove as much zinc as possible, calcined, mixed with a borax and silica flux and smelted in submerged arc furnaces. When smelting is complete the three carbon electrodes are raised mechanically and the furnace tilted for pouring into 1000 ounce $(31 \mathrm{~kg})$ bars. The product at this stage averages 10 per cent silver and 2 to 3 per cent of copper, iron, zinc and lead, with traces of the platinum metals.

Final refining is carried out in the Rand Refinery, where a modernisation programme has been completed resulting in virtually an entirely new plant. Its operations were briefly described in Gold Bulletin in April 1971 , but in the present book a fully detailed account is given of both the chlorine refining and the electrolytic refining procedures and of the rapid and economical handling of a very large output of refined gold.

A further section reviews recent progress in instrumentation and process control in South African gold plants, while a chapter on the chemistry of gold extraction includes an intriguing discussion on the use of Pourbaix diagrams in predicting the behaviour of gold in various conditions and in the selection of reagents and conditions that will favour its dissolution or alternatively its precipitation from solution.

As Sir Thomas Rose wrote in the preface to his "Metallurgy of Gold" many years ago:

"The most important function which a book on metallurgy has to fulfil is to help those who are taking part in attempts to improve the existing practice."

The present work certainly complies with this prescription as well as constituting a standard text for the student and the research worker.

L. B. $\mathbf{H}$, 